\title{
Comparison of transfer parameters in TRS-472 and Canadian standard CSA N288.1 and doses predicted using them
}

\author{
S.L. Chouhan, D. Rowan and M. Stuart \\ Environmental Technologies Branch, Atomic Energy of Canada Limited (AECL), Chalk River, \\ Ontario, KOJ 1J0, Canada, \\ e-mail: Chouhans@aecl.ca
}

\begin{abstract}
We compared parameter values and models in N288.1 and TRS-472 and the doses predicted using them. The parameter values and models for tritium and C-14 are similar. For other radionuclides, the parameter values agree well for soil to plant transfer, and forage to animal products transfer. Agreement is not always good for the translocation factor (for which N288.1 is often more conservative) and for soil and sediment $\mathrm{K}_{d}$ and freshwater fish BAFs (for which $\mathrm{N} 288.1$ is often less conservative). Using parameter values from N288.1 rather than using those from TRS-472 results in higher doses for 8 of 9 radionuclides for airborne releases, and for 5 of 9 radionuclides for aquatic releases. For airborne releases, the maximum difference occurs for I-131, where using N288.1 parameter values results in doses being seven times higher. For aquatic releases, the difference reaches a factor of 194 for Co-60, with the use of N288.1 parameter values resulting in the lower dose. Where differences exist, site-specific values for key radionuclides should be obtained through a review of available data or new experiments. In the absence of site-specific data, the more conservative of the values in N288.1 and TRS-472 should be used.
\end{abstract}

\section{INTRODUCTION}

The documents CSA N288.1 [1] and TRS-472 [2] contain models and transfer parameter values for predicting doses to humans from routine releases of radioactivity to airborne and aquatic pathways. In a CANDU Owners Group funded study, we compared: (1) parameter values for all radionuclides from both documents, (2) model structures for tritium and ${ }^{14} \mathrm{C}$, and (3) predicted doses for HTO, C-14, Co-60, Sr-90, Zr-95, Nb-95, I-131, Cs-134 and Cs-137 using a common model (N288.1) but parameter values from N288.1 and TRS-472.

The Canadian Standard N288.1, "Guidelines for calculating derived release limits for radioactive material in airborne and liquid effluents for normal operation of nuclear facilities", was developed by a group of Canadian experts and addresses Canadian conditions. It contains a complete model that starts from release rates to air and water, models atmospheric and aquatic dispersion, and predicts concentrations in all environmental compartments and doses to humans from all exposure pathways. It shares many parameter values with IAEA's TRS-364 [3], "Handbook of parameter values for the prediction of radionuclide transfer in temperate environments". Additional parameter values came from site-specific data. The tritium and C-14 models of N288.1 have been validated with experimental data $[4,5]$. TRS-472, "Handbook of parameter values for the prediction of radionuclide transfer in terrestrial and freshwater environments", which superseded TRS-364, is intended to provide conservative parameter values for screening, and considers the same environmental compartments as N288.1. It was developed by a team of international experts but generally reflects European conditions. TRS-472 contains models for transport of tritium and C-14, but not for other radionuclides. It has no equations for atmospheric or aquatic dispersion or dose prediction for any radionuclide.

\section{COMPARISON OF MODELS AND PARAMETER VALUES FOR TRITIUM AND C-14}

The calculations were done using the Canadian code CSA-DRL, which is based on N288.1. The airborne release scenario assumed $1 \mathrm{~Bq} \mathrm{~m}^{-3}$ air concentration of HTO (tritiated water) and C-14 and considered 


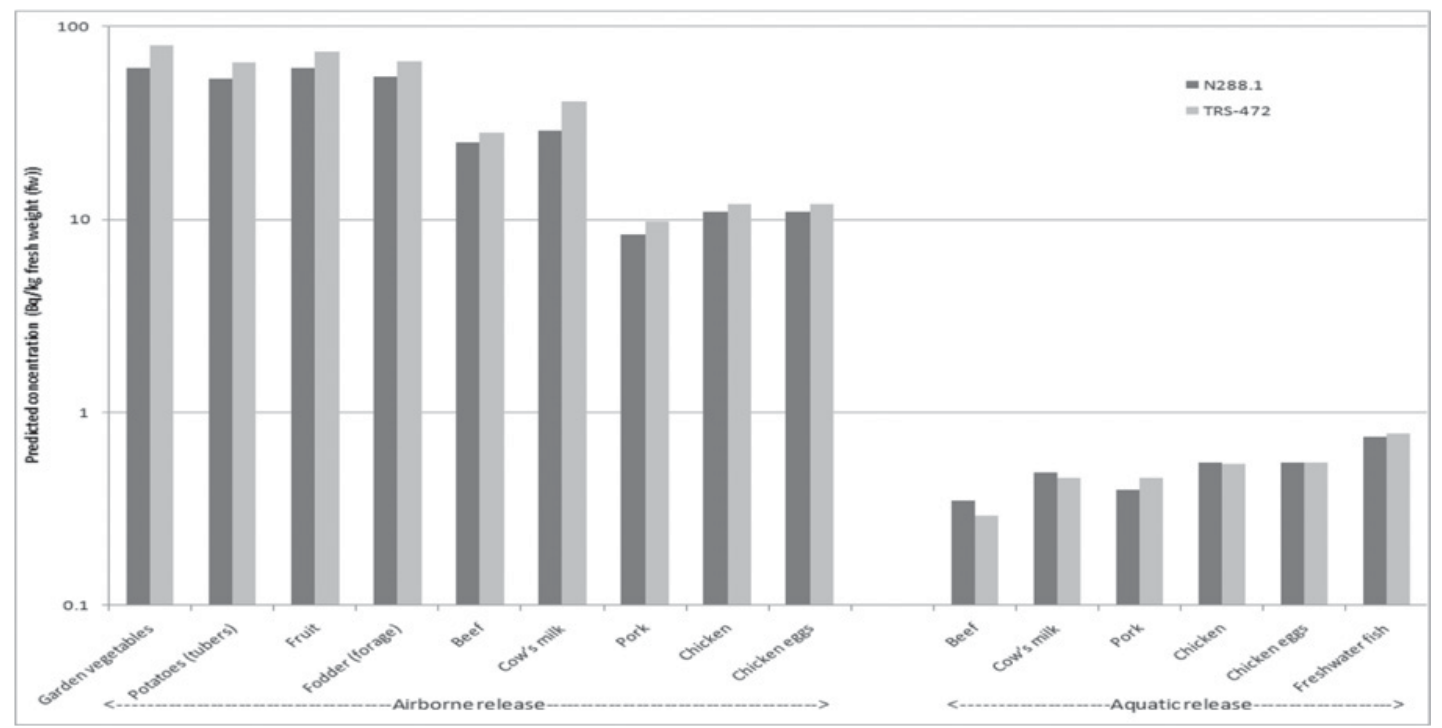

Figure 1. Comparison of food product HTO concentrations predicted using models and parameter values from N288.1 and TRS-472.

uptake by plants, and uptake by animals through ingestion of plants, assuming all feed is contaminated and drinking water is not contaminated. Air inhalation by terrestrial animals was considered in N288.1 but not in TRS-472. The aquatic release scenario assumed a water concentration of $1 \mathrm{~Bq} \mathrm{~L}^{-1} \mathrm{HTO}$ and C-14 and considered (1) uptake by animals through drinking contaminated water, assuming feed and air to be uncontaminated; and (2) uptake by fish from water. The predictions based on N288.1 and TRS472 (Figures 1-3) are similar, except that N288.1 predicts substantially higher concentrations for OBT (organically bound tritium) in animal products for aquatic releases, and for C-14 in animal products for airborne releases. In both models, animals are assumed not to take up C-14 from drinking water.

\section{COMPARISON OF PARAMETER VALUES FOR ALL OTHER RADIONUCLIDES}

The parameter values of N288.1 and TRS-472 are compared in Table 1. For the most part, very large differences are not observed because both documents rely heavily on information from TRS-364. The soil to plant transfer factors $(\mathrm{CR})$ and forage to animal products transfer factors $\left(\mathrm{F}_{\text {ing }}\right)$ values are in excellent agreement between N288.1 and TRS-472, and where differences exist, the values in N288.1 are generally conservative in the sense that they lead to higher predicted doses.

The translocation factor (tf) is excessively conservative in $\mathrm{N} 288.1$ for many radionuclides.

The soil and sediment partition coefficients $\left(\mathrm{K}_{d}\right)$ values are significantly different between N288.1 and TRS-472 for many radionuclides. The soil $\mathrm{K}_{d}$ values in $\mathrm{N} 288.1$ are usually lower than those in TRS472 and so are more conservative for soil-plant transfer but less conservative for groundwater pathways. Soil $\mathrm{K}_{d}$ values are known to be highly variable among soils and experimental methodologies, but the use of site and soil specific values can reduce this uncertainty. Freshwater sediment $\mathrm{K}_{d}$ values in N288.1 tend to be lower (less conservative) than those in TRS-472, as are the soil $\mathrm{K}_{d}$ values for groundwater pathways.

N288.1 is less conservative than TRS-472 for freshwater fish bioaccumulation factors (BAF) for 4 of the 7 radionuclides for which values in the two documents differ by more than a factor of 10. Site-specific BAF values for these radionuclides $(\mathrm{Hg}, \mathrm{Pu}, \mathrm{Se}$ and $\mathrm{U})$ should be obtained. The 


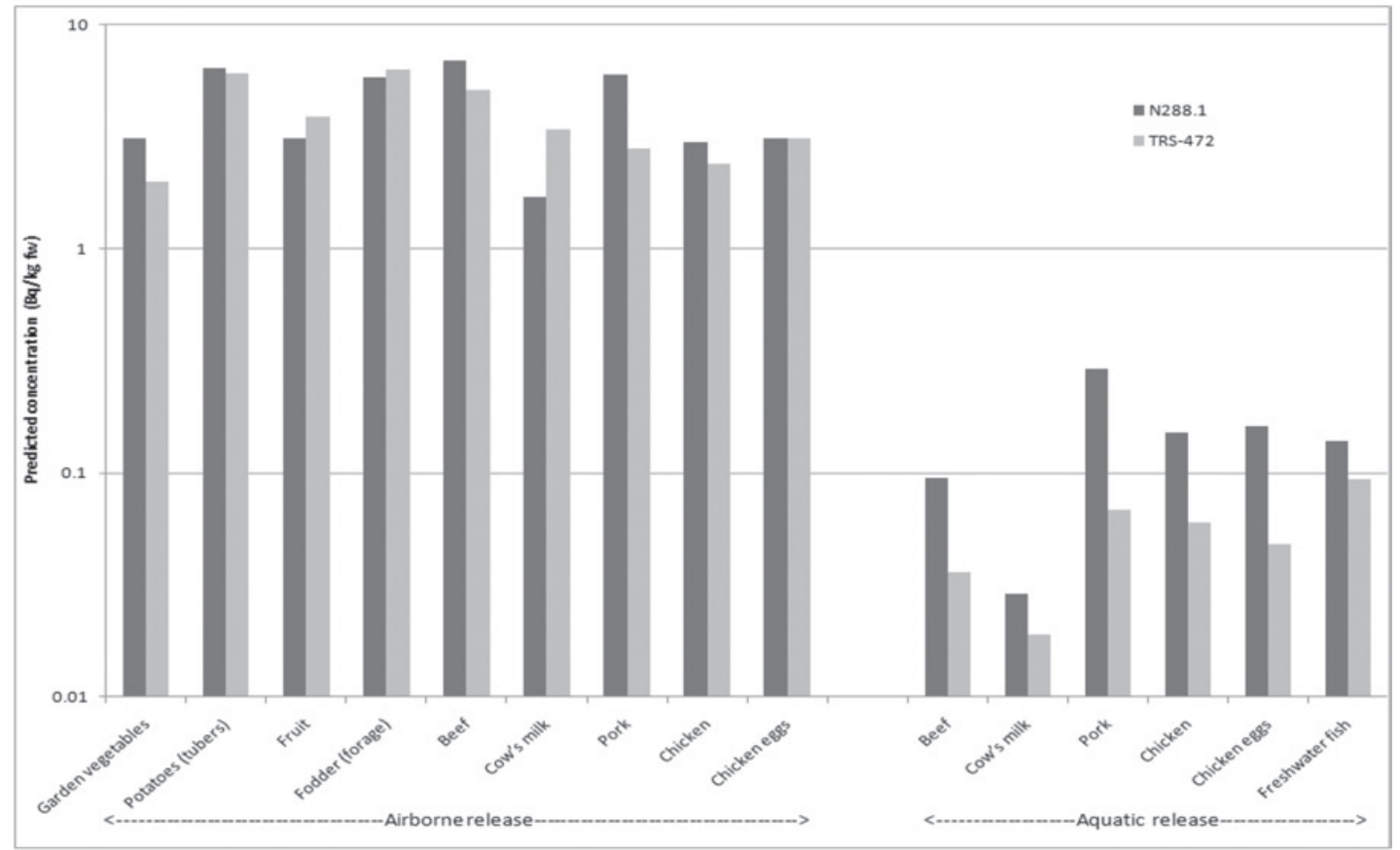

Figure 2. Comparison of food product OBT concentrations predicted using models and parameter values from N288.1 and TRS-472.

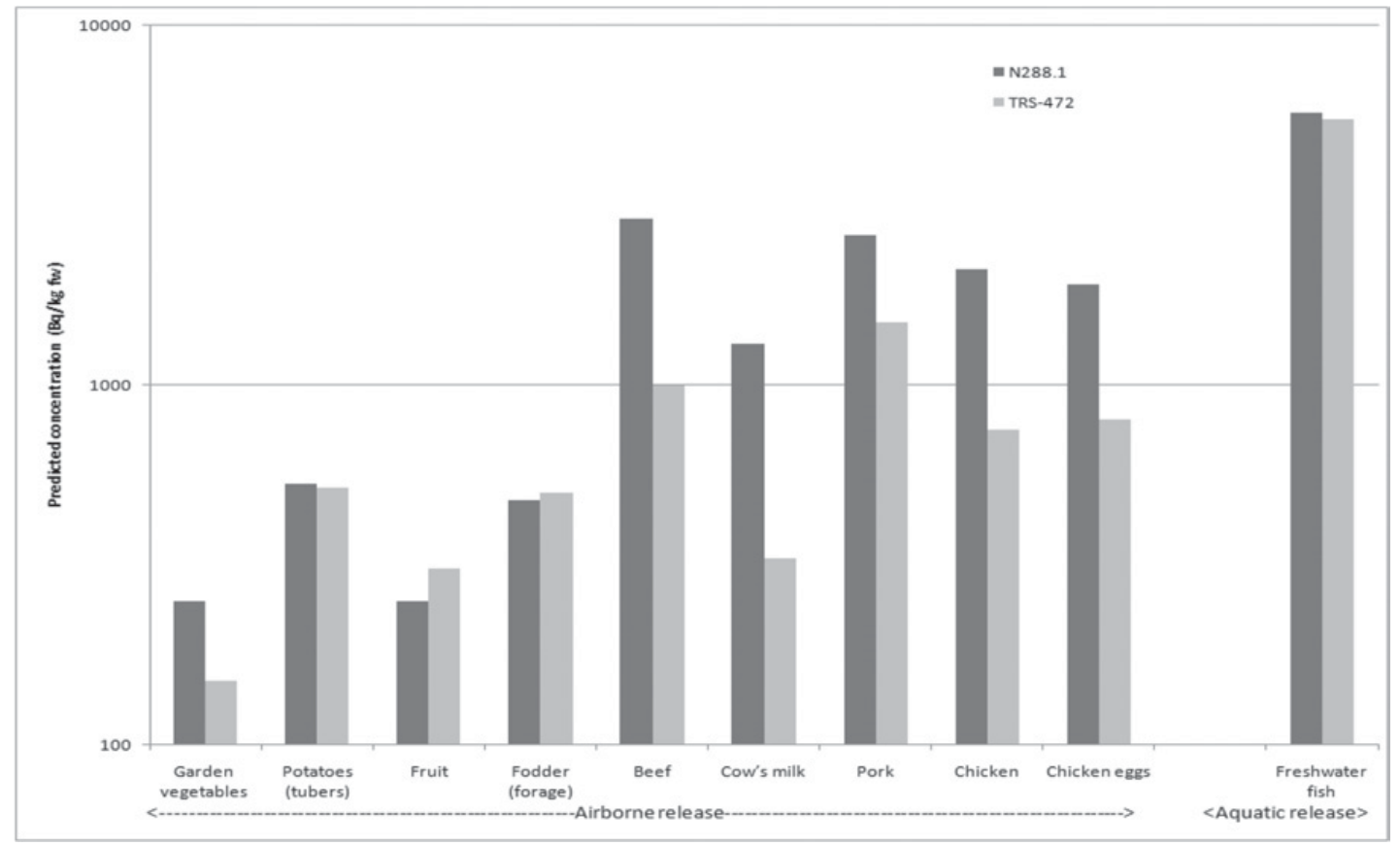

Figure 3. Comparison of food product $\mathrm{C}-14$ concentrations predicted using models and parameter values from N288.1 and TRS-472. 
Table 1. Comparison of parameter values. Hatched shading indicates N288.1 is less conservative than TRS-472 by more than a factor of 10; black shading indicates N288.1 is more conservative than TRS-472 by more than a factor of 10; grey shading indicates agreement within a factor of 10; white cells indicate no data in TRS-472.

\begin{tabular}{|c|c|c|c|c|c|c|c|c|c|c|c|c|}
\hline element & tf & $\begin{array}{c}\mathrm{K}_{\mathrm{d}} \\
\text { (soil) }\end{array}$ & $\begin{array}{c}\text { CR } \\
\text { (soil/ } \\
\text { plant) }\end{array}$ & $\begin{array}{l}F_{\text {ing }} \\
\text { (cow } \\
\text { milk) }\end{array}$ & $\begin{array}{c}\mathrm{F}_{\text {ing }} \\
\text { (goat } \\
\text { milk) }\end{array}$ & $\begin{array}{c}F_{\text {ing }} \\
\text { (beef) }\end{array}$ & $\begin{array}{c}F_{\text {ing }} \\
\text { (lamb) }\end{array}$ & $\begin{array}{c}F_{\text {ing }} \\
\text { (pork) }\end{array}$ & $\begin{array}{c}\mathrm{F}_{\text {ing }} \\
\text { (poultry) }\end{array}$ & $\begin{array}{c}F_{\text {ing }} \\
\text { (eggs) }\end{array}$ & $\begin{array}{c}\mathrm{K}_{\mathrm{d}} \\
\text { (sed) }\end{array}$ & $\begin{array}{l}\text { BAF } \\
\text { (fish) }\end{array}$ \\
\hline $\mathrm{Ag}$ & & & & & & & & & & & AXd & \\
\hline \multicolumn{13}{|c|}{ 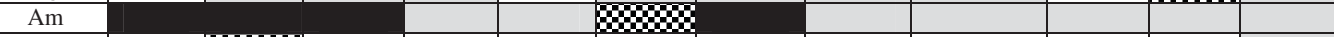 } \\
\hline \multicolumn{13}{|l|}{ As } \\
\hline \multicolumn{13}{|l|}{$\mathrm{Ba}$} \\
\hline \multicolumn{13}{|c|}{$\omega N$} \\
\hline \multicolumn{13}{|l|}{$\mathrm{Br}$} \\
\hline \multicolumn{13}{|c|}{ AX } \\
\hline \multicolumn{13}{|l|}{$\mathrm{Cl}$} \\
\hline \multicolumn{13}{|l|}{$\mathrm{Cm}$} \\
\hline \multicolumn{13}{|c|}{ 19X } \\
\hline \multicolumn{13}{|l|}{$\mathrm{Cr}$} \\
\hline \multicolumn{13}{|l|}{ Cs } \\
\hline \multicolumn{13}{|l|}{$\mathrm{Eu}$} \\
\hline \multicolumn{13}{|c|}{ W010 } \\
\hline \multicolumn{13}{|l|}{$\mathrm{Hf}$} \\
\hline \multicolumn{13}{|c|}{ 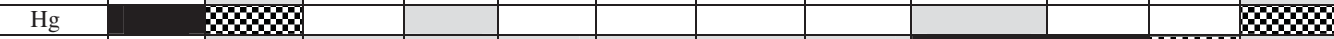 } \\
\hline \multicolumn{13}{|l|}{ I } \\
\hline \multicolumn{13}{|l|}{ In } \\
\hline \multicolumn{13}{|l|}{$\mathrm{La}$} \\
\hline $\mathrm{Mn}$ & & 120 & & & & & & & & & 100 & \\
\hline Mo & & & & & & & & & & & & \\
\hline $\mathrm{Na}$ & & & & & & & & & & & & \\
\hline $\mathrm{Nb}$ & & & & & & & & & & & & \\
\hline $\mathrm{Ni}$ & & & & & & & & & & & & \\
\hline $\mathrm{Np}$ & & & & & & & & & & & & \\
\hline $\mathrm{P}$ & & & & & & & & & & & & \\
\hline $\mathrm{Pa}$ & & & & & & & & & & & & \\
\hline $\mathrm{Pm}$ & & & & & & & & & & & & \\
\hline $\operatorname{Pr}$ & & & & & & & & & & & & \\
\hline $\mathrm{Pu}$ & & & & & & & & & & & WX & $\mathbf{N \alpha}$ \\
\hline $\mathrm{Ra}$ & & & & & & & & & & & & \\
\hline $\mathrm{Rb}$ & & & & & & & & & & & & \\
\hline $\mathrm{Rh}$ & & & & & & & & & & & & \\
\hline $\mathrm{Ru}$ & & & & & & & & & & & 100 & \\
\hline $\mathrm{S}$ & & & & & & & & & & & & \\
\hline $\mathrm{Sb}$ & & & & & & & & & & & 100 & \\
\hline $\mathrm{Sc}$ & & WX & & & & & & & & & & \\
\hline $\mathrm{Se}$ & & & & & & & & & & & & 202 \\
\hline Sn & & & & & & & & & & & & \\
\hline $\mathrm{Sr}$ & & 100 & & & & & & & & & & \\
\hline $\mathrm{Tb}$ & & & & & & & & & & & & \\
\hline $\mathrm{Tc}$ & & & & & & & & & & & & \\
\hline $\mathrm{Te}$ & & & & & & & & & & & & \\
\hline Th & & & & & & & & & & & & \\
\hline $\mathrm{U}$ & & & & & & & & & & & & 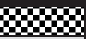 \\
\hline $\mathrm{Y}$ & & & & & & & & & & & & \\
\hline $\mathrm{Zn}$ & & & & & & & & & & & & \\
\hline $\mathrm{Zr}$ & & & & & & & & & & & & \\
\hline
\end{tabular}

TRS-472 equation for estimating cesium BAF values from potassium concentrations in water should be re-evaluated using data from Rowan and Rasmussen [6].

For three radionuclides ( $\mathrm{Am}, \mathrm{Pu}$ and $\mathrm{Ru}$ ), values for more than three parameters differ by more than a factor of 10 between N288.1 and TRS-472. The only parameter for which TRS-472 provides a value for $\mathrm{Eu}$ is the BAF.

\section{DOSE PREDICTIONS}

The effect of different parameter values on the doses predicted by N288.1 was studied for the scenarios discussed above. The total doses to humans were predicted and compared (Figure 4) for nine 


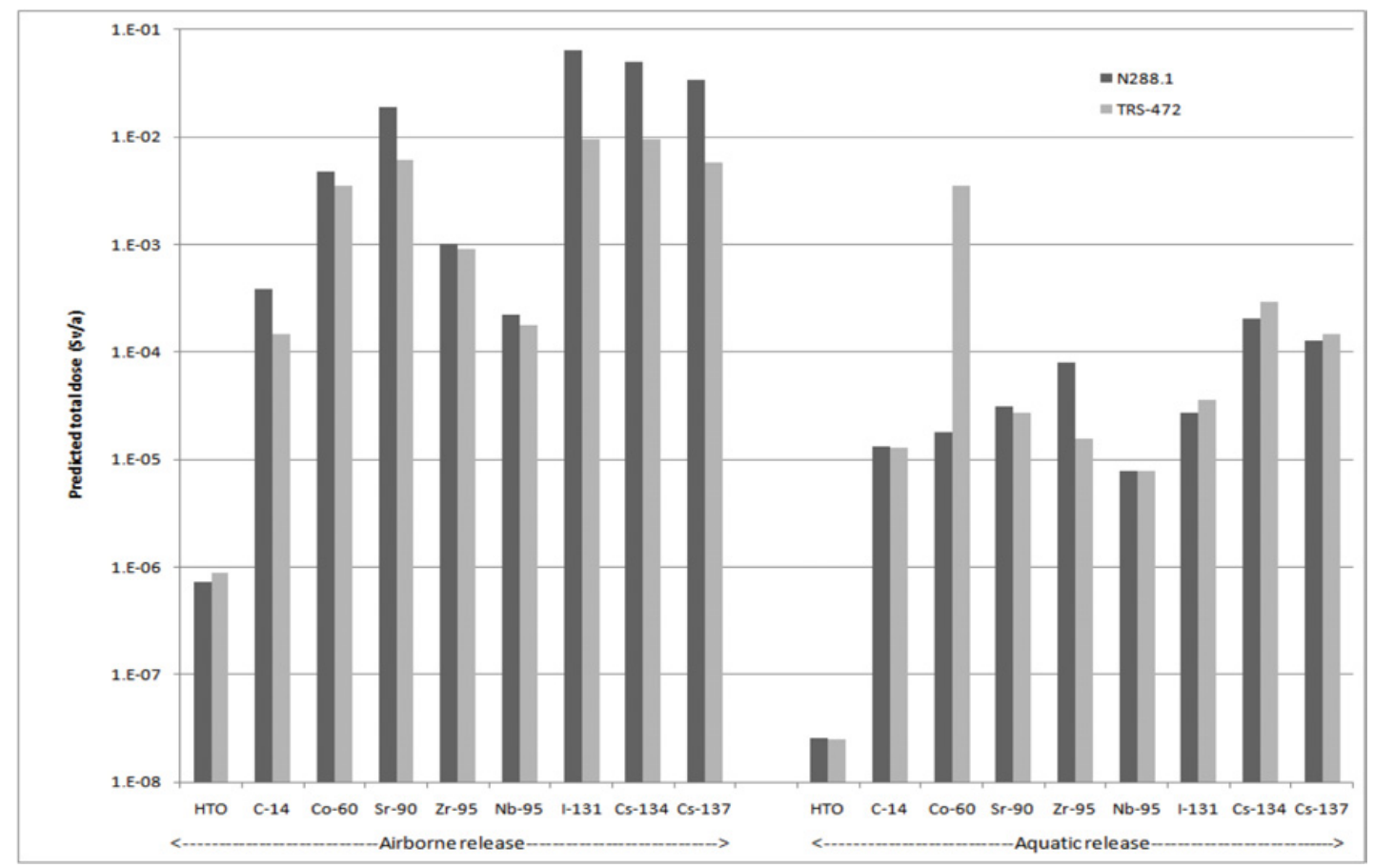

Figure 4. Comparison of total dose from airborne and aquatic releases predicted using the same model (N288.1) but the parameter values from N288.1 and TRS-472.

radionuclides, first using the parameter values from N288.1 and then those from TRS-472. Using the parameter values from N288.1 results in higher dose than using those from TRS-472 for 8 of the 9 radionuclides for airborne releases, and for 5 of the 9 radionuclides for aquatic releases. For airborne releases, the maximum difference occurs for I-131, where using the N288.1 parameter values produce doses seven times higher than those calculated using the TRS-472 values, primarily due to the very conservative value for tf. For aquatic releases, the difference reaches a factor of 194 for Co-60, with use of the N288.1 parameter values resulting in the lower dose, largely due to the very low sediment $\mathrm{K}_{d}$ value.

\section{CONCLUSIONS AND RECOMENDATIONS}

TRS-472 is a useful compilation of updated transfer parameters. In general, there is excellent agreement between the values in TRS-472 and N288.1, particularly with respect to CR and $F_{\text {ing. Where differences }}$ exist for these parameters, N288.1 is usually more conservative. The parameters that have the most instances of significant disagreement between N288.1 and TRS-472 are the translocation factor, soil and sediment $\mathrm{K}_{d}$ and freshwater fish BAF. The $\mathrm{K}_{d}$ and BAF values in N288.1 are generally less conservative than those in TRS-472. Disagreement is most frequent for $\mathrm{Am}, \mathrm{Eu}$ and $\mathrm{Pu}$. TRS-472 provides a value for only one parameter for $\mathrm{Eu}$ (a BAF), and its estimate of the cesium BAF from potassium concentrations in water is based on limited data. The differences in parameter values carry over into differences in doses. The parameter values and doses for tritium and ${ }^{14} \mathrm{C}$ are similar. Parameter values that are not site-specific should be further rationalized in the two documents. The following recommendations 
are made:

- Soil $\mathrm{K}_{d}$

- Review supporting data for the values given in N288.1 and TRS-472.

- Compile and analyse site-specific or region-specific data.

- Conduct experiments on key radionuclides and site-specific soils, as necessary.

- Use the more conservative values in the absence of site- or region-specific data.

- Sediment Kd

○ Replace all values derived from soil with site-specific sediment values.

- Review existing site- and water body-specific data.

- Conduct experiments on beach sediments for key radionuclides to determine sitespecific values.

- Use TRS-472 values in the absence of site-specific or region-specific data.

- Fish BAF

- Augment the dataset of Chant et al. [7] with site-specific values for additional radionuclides.

- Develop a robust model to predict cesium BAF using data from Rowan and Rasmussen [6].

- Conduct further research on the environmental transport and fate of $\mathrm{Am}, \mathrm{Eu}, \mathrm{Pu}$ and $\mathrm{Ru}$.

N288.1 supplements TRS-472 by having a complete model of environmental radionuclide transport. In combination these documents provide useful models and parameter values for predicting radionuclide concentrations in environmental compartments and doses to humans.

\section{References}

[1] CSA., Guidelines for calculating derived release limits for radioactive material in airborne and liquid effluents for normal operation of nuclear facilities. CSA N288.1-08. (Canadian Standards Association, Mississauga 2008).

[2] IAEA., Handbook of parameter values for the prediction of radionuclide transfer in terrestrial and freshwater environments. TRS-472. (International Atomic Energy Agency, Vienna, 2010).

[3] IAEA., Handbook of parameter values for the prediction of radionuclide transfer in temperate environments. TRS-364. (International Atomic Energy Agency, Vienna, 1994).

[4] P.A. Davis, S.B. Kim, S.L. Chouhan and W.J.G. Workman., Observed and Modeled Tritium Concentrations in the Terrestrial Food Chain near a Continuous Atmospheric Source (Fusion Science and Technology Journal, 2005) Volume 48, Number 1, pp. 504-507.

[5] M. Audette-Stuart, S.L. Chouhan, S.J. Kramer-Tremblay, C. Shultz, K.J. Sharp, T.L. Yankovich and M.L. Benz. Validation of the Carbon Specific Activity Model in IMPACT Using Carbon-14 Environmental Data Collected in the Vicinity of PNGS During the Summer of 2002. COG-033047, 2004.

[6] D.J. Rowan, and J.B. Rasmussen, Bioaccumulation of radiocesium by fish: the influence of physicochemical factors and trophic structure. (Canadian Journal of Fisheries and Aquatic Sciences, 1994), 51: 2388-2410.

[7] L.A Chant, D.S. Hartwig and M. Totland, Site specific aquatic transfer factors for CANDU sites in Canada, AECL RC-2457, 2000. 